\title{
Epidemiological Aspects of Cutaneous Leishmaniasis during 2009-2016 in Kashan City, Central Iran
}

\author{
Doroodgar Moein', Doroodgar Masoud', Mahboobi Saeed², Doroodgar Abbas ${ }^{3, *}$ \\ ${ }^{1}$ School of Medicine, Shahid Beheshti University of Medical Sciences, Tehran, Iran; ${ }^{2}$ Kashan University of Medical Sciences, Vice Chancellor of \\ Health, Group of Communicable Diseases, Kashan, Iran; ${ }^{3}$ Department of Medical Parasitology, School of Medicine, Kashan University of Medical \\ Sciences, Kashan, Iran
}

\begin{abstract}
Cutaneous leishmaniasis (CL) can be seen in 2 forms, zoonotic and anthroponotic, in Iran. In this study, epidemiological aspects of CL were studied during an 8-year period (2009-2016) in city of Kashan, central Iran. The demographic and epidemiological data, including age, sex, occupation, number and site of the lesions, treatment regimen, past history of $\mathrm{CL}$, and season of all patients were gathered from the health centers. Descriptive statistics were used to describe features of the study data. Total 2,676 people with CL were identified. The highest annual incidence was estimated to be 182 per 100,000 population in 2009 and the least was in 2016 (47 per 100,000 population). The highest frequency affected age groups were observed in 20-29 year-old patients (20.9\%). More than $51 \%$ of the patients were under 30 years old. The maximum frequency of the disease, 1,134 (43.3\%), was seen in autumn. The most common location of lesions was hands $(61.4 \%)$. Most of the patients (81.6\%) were treated by systemic glucantime regimen. In the city of Kashan, the incidence rate of the $\mathrm{CL}$ disease is significantly higher than many other regions of Iran. To reduce the risk of disease, control of reservoir hosts and vectors of disease, and education of individual protection are strongly recommended.
\end{abstract}

Key words: Leishmania major, Leishmania tropica, cutaneous leishmaniasis, epidemiology, Iran

\section{INTRODUCTION}

Leishmaniasis is transmitted by the bite of infected female phlebotomine sand flies. It is estimated that there are 12 million cases of disease worldwide, and there are 0.9-1.3 million new cases annually [1]. There are about 20 distinct parasite species of Leishmania detected that cause leishmaniasis [2-4]. The clinical forms of the disease are wide from a self-limiting cutaneous lesion to a mutilating mucocutaneous disease [1,4]. World Health Organization (WHO) reported 97 countries as endemic leishmaniasis [5]. One of these diseases is cutaneous leishmaniasis (CL). Most cases of CL occur in Afghanistan, Algeria, Brazil, Colombia, the Islamic Republic of Iran, Pakistan, Peru, Saudi Arabia, and Syria [1,6]. In 2015, numbers of reported cases of cutaneous leishmaniasis were particularly high in the Islamic Republic of Iran [5]. Iran is one of the most important endemic areas, in which CL is observed in 2 forms;

\footnotetext{
- Received 8 October 2017, revised 23 December 2017, accepted 26 December 2017. *Corresponding author (adoroudgar@gmail.com) (C) 2018, Korean Society for Parasitology and Tropical Medicine This is an Open Access article distributed under the terms of the Creative Commons Attribution Non-Commercial License (http://creativecommons.org/licenses/by-nc/4.0) which permits unrestricted non-commercial use, distribution, and reproduction in any medium, provided the original work is properly cited.
}

zoonotic CL (ZCL) and anthroponotic CL (ACL). They are caused by Leishmania major and Leishmania tropica, respectively $[4,7]$. At present, CL is the most important vector-borne disease and is seen in many parts of Iran $[8,9]$. ZCL is endemic in 17 out of 31 provinces of Iran. One of these provinces is Isfahan, which ZCL is endemic in many rural areas [10,11]. Kashan is one of the largest cities in Isfahan Province where CL has become widespread. This study was carried out to determine the prevalence of this disease in Kashan city in an 8-year period, during 2009-2016.

\section{MATERIALS AND METHODS}

To examine the prevalence of $\mathrm{CL}$, this cross sectional study was carried out during 2009-2016 in the city of Kashan. The data of 2,676 CL cases referred to health centers of Kashan University of Medical Sciences were collected. The patients were introduced to the laboratory by physician after an earlydetection examination. For the diagnosis of $\mathrm{CL}$, the direct smear technique has been used. The samples were taken from patient's lesions by clinical staff and then examined under a light microscope for signs of Leishman parasite. All data obtained were recorded in researcher-constructed checklists and 
the SPSS version 24 (Chicago, Illinois, USA) for Windows was used to perform a chi-square test for relationships between variables. The checklist used included patients' demographic characteristics such as age, gender, occupation, place or number of acute lesion(s), date of occurrence of lesion(s), history of travel in the past to other endemic foci of the disease, location of residence, results of clinical examination and laborato-

Table 1. Distribution of cutaneous leishmaniasis (CL) disease characters in 2,676 patients in the city of Kashan, 2009-2016

\begin{tabular}{|c|c|c|}
\hline Characters & Categories & $\begin{array}{c}\text { No. }(\%) \text { of } \\
\text { patients with } \mathrm{CL}\end{array}$ \\
\hline Year & $\begin{array}{l}2009 \\
2010 \\
2011 \\
2012 \\
2013 \\
2014 \\
2015 \\
2016\end{array}$ & $\begin{array}{l}562(21.0) \\
395(14.8) \\
316(11.8) \\
348(13.0) \\
299(14.9) \\
377(14.1) \\
203(7.6) \\
176(6.6)\end{array}$ \\
\hline Gender & $\begin{array}{l}\text { Male } \\
\text { Female }\end{array}$ & $\begin{array}{l}1,550(58.0) \\
1,126(42.0)\end{array}$ \\
\hline Age group & $\begin{array}{l}0-9 \\
10-19 \\
20-29 \\
30-39 \\
40-49 \\
50-59 \\
\geq 60\end{array}$ & $\begin{array}{l}365(13.6) \\
457(17.1) \\
558(20.9) \\
380(14.2) \\
335(12.5) \\
238(8.9) \\
343(12.8)\end{array}$ \\
\hline Occupation & $\begin{array}{l}\text { Housewife } \\
\text { Student } \\
\text { Worker } \\
\text { Child } \\
\text { Farmer } \\
\text { Driver } \\
\text { Other }\end{array}$ & $\begin{array}{c}727(27.2) \\
482(18.0) \\
354(13.2) \\
249(9.3) \\
94(3.5) \\
48(1.8) \\
722(27.0)\end{array}$ \\
\hline Location of residence & $\begin{array}{l}\text { Urban } \\
\text { Rural }\end{array}$ & $\begin{array}{c}2,455(91.7) \\
221(8.3)\end{array}$ \\
\hline Nationality & $\begin{array}{l}\text { Iranian } \\
\text { Non-Iranian }\end{array}$ & $\begin{array}{r}2,402(89.8) \\
274(10.2)\end{array}$ \\
\hline Travel history & $\begin{array}{l}\text { Yes } \\
\text { No }\end{array}$ & $\begin{array}{l}1,053(39.3) \\
1,623(60.7)\end{array}$ \\
\hline Season & $\begin{array}{l}\text { Spring } \\
\text { Summer } \\
\text { Autumn } \\
\text { Winter }\end{array}$ & $\begin{array}{r}485(18.1) \\
534(20.0) \\
1,134(42.4) \\
523(19.5)\end{array}$ \\
\hline Place of Lesion & $\begin{array}{l}\text { Hands } \\
\text { Feet } \\
\text { Face } \\
\text { Trunk } \\
\text { Other places }\end{array}$ & $\begin{array}{c}1,646(61.5) \\
441(16.4) \\
487(18.1) \\
64(2.4) \\
44(1.6)\end{array}$ \\
\hline Treatment & $\begin{array}{l}\text { Systemic glucantime } \\
\text { Topical glucantime } \\
\text { Topical glucantime \& } \\
\text { Cryotherapy } \\
\text { Cryotherapy } \\
\text { Not indicated } \\
\text { Other }\end{array}$ & $\begin{array}{r}2,183(81.6) \\
306(11.4) \\
43(1.6) \\
\\
102(3.8) \\
13(0.5) \\
29(1.1)\end{array}$ \\
\hline
\end{tabular}

ry tests, the type of treatment regimen, and nationality of patients. Data were analyzed using SPSS version 24 for windows.

\section{RESULTS}

During the 8-year period (2009-2016), total 2,676 cases of CL were reported. Of these, $42 \%$ were female and $58 \%$ were male. The chi-square test showed that there was no significant association between the sex and the disease $(P>0.05)$. The disease had the highest frequency $(20.9 \%)$ in $20-29$ age groups and the lowest (8.9\%) were seen in 50-59 age groups. No significant correlation was found between age groups and active disease. Among the patients, $51.6 \%$ were under 30 years old (Table 1). Only $1.1 \%$ were 1 -year-old or less. The youngest was only 1-month old, and the oldest patient was 95 years old.

The location of lesions was different; $61.5 \%$ of the patients had a lesion on their hands, $18.1 \%$ on face, $16.4 \%$ on feet, $2.4 \%$ on trunk, and $1.6 \%$ in other places of the body. About $1 / 3(37.3 \%)$ of these patients had multiple lesions spread all over their bodies. A maximum of 20 wounds were seen in 1 patient. Also, most patients (62.7\%) had a single lesion. Most patients $(91.7 \%)$ lived in urban areas $(P=0.001)$. The highest rate of lesion according to the occupation was observed in housewives (27.2\%). There was no significant relationship between the occupation and disease $(P=0.062)$. The most common location of lesions was on hands (61.4\%) and then on face $(16.4 \%)$, on feet $(16.4 \%)$ and on the other parts of the body (Table 1). Some (39.3\%) cases had a history of travel to endemic areas, and $92 \%$ and $8 \%$ were living in urban and rural areas, respectively.

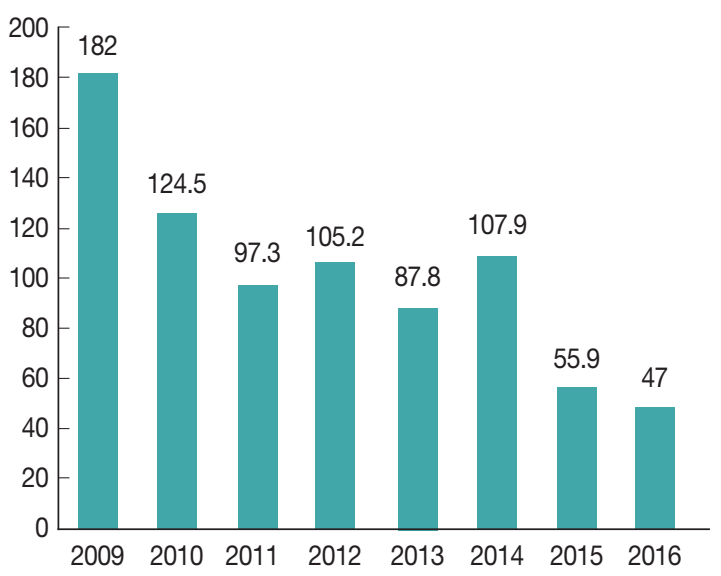

Fig. 1. Cutaneous leishmaniasis (CL) disease annual incidence rate per 100,000 populations in the city of Kashan between 20092016. 
The highest number of cases (21\%) was seen in 2009 and the lowest (6.6\%) in 2016 (Table 1). The highest annual incidence was estimated to be 182 per 100,000 in 2009 and the least was 47 per 100,000 in 2016 (Fig. 1). The most frequent prevalence of cases was seen in autumn (42.4\%), and the least was seen in spring (18.1\%). Most of the patients (81.6\%) were treated by systemic glucantime regimen (Table 1 ). There was a significant difference between the treatment regimen and the disease $(P=0.000)$.

\section{DISCUSSION}

This report aimed to provide epidemiological information on CL in city of Kashan over the past 8 years (2009-2016). During this period, total 2,676 CL cases were detected. In recent years, the incidence of CL showed a significant decrease; however, CL is still a public health problem.

In this study, both sexes were susceptible to the disease. However, the incidence of the disease was more common in the male gender (58\%). Other investigations in Iran, Kermanshah and Fars Province, reported similar findings [12-15]. Higher incidence of the disease in men could be due to multiple factors such as habits of wearing clothes, business, travel to endemic regions, inadequate health education, environmental factors, and vector related factors. In relation with the occupational groups, the highest frequency (27.2\%) was observed in housewives. Our findings were consistent with the results of the studies in Qom Province and in urban and rural provinces in Iran $[10,13]$. The higher levels of contamination in housewives can be attributed to economic activities related to carpet weaving. Many housewives are knitting handmade carpet in low-light basements or rooms. Sandflies can continue bloodsucking activities under this condition throughout the day [4]. Our study showed that the highest incidence of CL occurred in 20-29 year-old age group. Findings in Kermanshah, Fars Province and Kashan were consistent with the results of the present study [14-16]. However, our results were inconsistent with studies performed in Qom, Razavi Khorasan, south western Iran $[10,17,18]$. In the Kashan region, Since the reservoir hosts and humans contacts with sandflies are high and the endemicity of $\mathrm{CL}$ is low; the disease occurred in all age groups, and the disease was more common in the age group of 20-29 years (20.9\%).

Regarding the seasonal tendency, we found that the highest prevalence occurred in autumn. Our result is consistent with findings in Qom, Fars Province and Yazd studies [10,14,19]. However, in Kermanshah, the majority of CL were observed in winter [15]. This finding is inconsistent with the result of the current study. Increase of CL cases in autumn can be associated with the incubation period of the disease, climatic conditions, sandfly peak activities, and blood-sucking of the victims.

The CL lesions may occur in any part of the body, and there are various reports on unusual sites $[7,21]$. In this study, the most common place was hands (61.4\%). Our findings are similar to the results of 2 studies in Iran and the cities of Kashan and Ahvaz $[12,13,16,20]$. Since hands are often uncoated and easily exposed to infected female sandfly bites, hands show a higher frequency of lesions than other parts of the body.

In the present study, $62.7 \%$ patients had only 1 lesion. Since $37.3 \%$ patients had 2 or more lesions, we could conclude that the victim has one or more time bites by sandflies. In addition, we observed that $39.3 \%$ of patients had a history of travel to endemic regions. Therefore, the majority of patients $(60.7 \%)$ have been infected in the place of residence.

We found out that the most preferred treatment regimen $(81.6 \%)$ is systemic meglumine antimonate (Glucantime). This is not consistent with the results of a study conducted in Libya [22]. Since pentavalent antimony compounds are the first line drug against all forms of leishmaniasis [23], this treatment regimen was taken by physicians for treating CL lesions in the city of Kashan. Antimony compounds have some limitations, such as toxicity, resistance, and long duration of treatment. To cover these disadvantages, investigators are trying to evaluate different compounds [24].

The highest incidence of CL was estimated in 2009 (182 per 100,000 people) and the least in 2016 (47 per 100,000 people). The results of a study conducted in Iran showed that the incidence of CL was 27.5 per 100,000 populations [13]. The incidence of CL in the city of Kashan was higher than expected and compared with the prevalence of CL in Iran. The CL incidence has declined in the last 2 years (2015-2016). The declining trend might be due to significant activities undertaken in CL control program, including control of the parasite vectors and reservoir hosts, early diagnosis and treatment of the disease, and increasing people's awareness on the use of personal protection methods. The results of our study confirmed that $\mathrm{CL}$ is endemic in many parts of rural and urban areas of Kashan district. According to many reasons, including socioeconomic and psychological problems, the disease should be 
controlled. To control the disease, much attention should be given to improve the environment conditions and public health education.

\section{ACKNOWLEDGMENT}

The authors would like to thank and appreciate all of those who collaborated with the authors during this research.

\section{CONFLICT OF INTEREST}

The authors declare that there is no conflict of interest.

\section{REFERENCES}

1. World Health Organization. Leishmaniasis: the disease and epidemiological situation. [Internet]. Available from: http://www. who.int/leishmaniasis/disease_epidemiology/en/.

2. Sadeghi-Nejad B, Saki J. Effect of aqueous Allium cepa and Ixora brachiate root extract on Leishmania major promastigotes. Jundishapur J Nat Pharm Prod 2014; 9: e15442.

3. Estevez Y, Castillo D, Pisango MT, Arevalo J, Rojas R, Alban J, Deharo E, Bourdy Gv, Sauvain M. Evaluation of the leishmanicidal activity of plants used by Peruvian Chayahuita ethnic group. J. Ethnopharmacol 2007; 114: 254-259.

4. Service M. Medical Entomology for Students. 4th ed. Cambridge, UK. Cambridge University Press. 2009, p 98.

5. World Health Organization. Leishmaniasis: situation and trends [Internet]. Available from: http://www.who.int/gho/neglected_ diseases/leishmaniasis/en/.

6. Postigo JA. Leishmaniasis in the World Health Organization Eastern Mediterranean Region. Int J Antimicrob Agents 2010; 36 (suppl): 62-65.

7. Doroodgar Masoud, Doroodgar Moein, Doroodgar Abbas. Unusual presentation of cutaneous leishmaniasis: ocular leishmaniasis. Case Rep Infect Dis 2017; 2017: 3198547.

8. Yaghoobi-Ershadi MR. Phlebotomine sand flies (Diptera: Psychodidae) in Iran and their role on Leishmania transmission. J Arthropod-Borne Dis 2012; 6: 1-17.

9. Shirzadi M, Mohebalih M, Yaghoobi-Ershadi MR, Firooz AR, Sharifi E, Fekree AR. Guidelines of care for cutaneous leishmaniasis in Iran. Tehran, Iran. Advertising Center Negahe Armani Press. 2012, p 114 (in Persian).

10. Rassi Y, Saghafipour A, Abai MR, Oshaghi MA, Mohebali M, Mostafavi R. Determination of Leishmania parasite species of cutaneous leishmaniasis using PCR method in central county, Qom Province. Zahedan J Res Med Sci 2013; 15: 13-16.
11. Yaghoobi-Ershadi MR. Control of phlebotomine sand flies in Iran: a review article. J Arthropod-Borne Dis 2016; 10: 429-444.

12. Khazaei S, Hafshejani AM, Saatchi M, Salehiniya H, Nematollahi S. Epidemiological aspects of cutaneous leishmaniasis in Iran. Arch Clin Infect Dis 2015; 10: e28511.

13. Norouzinezhad F, Ghaffari F, Norouzinejad A, Kaveh F, Gouya MM. Cutaneous leishmaniasis in Iran: results from an epidemiological study in urban and rural provinces. Asian Pac J Trop Biomed 2016; 6: 614-619.

14. Hamzavi Y, Khademi N. Trend of cutaneous leishmaniasis in Kermanshah Province, west of Iran from 1990 to 2012. Iran J Parasitol 2015; 10: 78-86.

15. Fathehi Bafghi AF, Eftekhari M, Ahmadi S, Moghateli M. Epidemiological pattern of cutaneous leishmaniasis in the province of Fars, Iran (since 2010-2014). JCHR 2016; 5: 240-248

16. Doroodgar Abbas, Sayyah M, Doroodgar Masoud, Mahbobi S, Nemetian M, Rafizadeh S, Rassi Y. Progressive increasing of cutaneous leishmaniasis in Kashan district, central of Iran. Asian Pac J Trop Dis 2012; 2: 260-263.

17. Khajedaluee M, Yazdanpanah MJ, SeyedNozadi S, Fata A, Juya MR, Masoudi MH, Najaf Najafi M. Epidemiology of cutaneous leishmaniasis in population covered by Mashhad University of Medical Sciences in 2011. Med J Mashhad Univ Med Sci 2014; 57: 647-654 (in Persian).

18. Feiz-Haddad MH, Kassiri H, Kasiri N, Panahandeh A, Lotfi M. Prevalence and epidemiologic profile of acute cutaneous leishmaniasis in an endemic focus, south western Iran. JAD 2015; 4: 292-297.

19. Yaghoobi-Ershadi MR, Marvi-Moghadam N, Jafari R, Akhavan AA, Solimani H, Zahrai-Ramazani AR, Arandian MH, DehghanDehnavi AR. Some epidemiological aspects of cutaneous leishmaniasis in a new focus, central Iran. Dermatol Res Pract 2015; 2015: 286408.

20. Vazirianzadeh B, Kamalvandi M, Shamsi J, Viesbehbahani R, Amraee K, Sollary SS. Epidemiology of cutaneous leishmaniasis in west of Ahvaz district, Khuzestan Province, southwestern of Iran. J Exp Zool India 2014; 17: 219-222.

21. Doroodgar Moein, Doroodgar Masoud, Doroodgar Abbas. Eyelid cutaneous leishmaniasis: a case report. Iran J Public Health 2017; 46: 261-264.

22. Abdellatif MZ, El-Mabrouk K, Ewis AA. An epidemiological study of cutaneous leishmaniasis in Al-jabal Al-gharbi, Libya. Korean J Parasitol 2013; 51: 75-84.

23. Frézard F, Demicheli C, Ribeiro RR. Pentavalent antimonials: new perspectives for old drugs. Molecules 2009; 14: 2317-2336.

24. Doroodgar Masoud, Delavari M, Doroodgar Moein, Abbasi A, Taherian AA, Doroodgar Abbas. Tamoxifen induces apoptosis of Leishmania major promastigotes in vitro. Korean J Parasitol 2016; 54: 9-14. 